\title{
Web-based Decision Support System to Evaluate the Living Conditions: A Case Study of the Colombo City
}

\author{
E.M.R.D Ekanayaka ${ }^{*}$ and G.S.N Perera ${ }^{1}$ \\ ${ }^{1}$ Faculty of Geomatics, Sabaragamuwa University of Sri Lanka, Belihuloya, Sri Lanka \\ *richierde@gmail.com
}

\begin{abstract}
Colombo city hosts almost eight hundred thousand people from various parts of the world and it is one of the fastest growing cities in the Asian continent. The city subjects to heavy migration because of urbanization. Due to this reason, the living conditions also vary from place to place in the city. The immigrants are often concerned about their mobility and accessibility to different civic services. Hence, selection of a living area becomes an important factor for an inhabitant physically, mentally and financially. However, systematic methodology has not been implemented to evaluate these living conditions. This study explicates utilizing of hotspot analysis and Network Analysis extension of ArcGIS to extrapolate crime and the accessibility to six fundamental civic services including education, healthcare, public parks, shopping centres and emergency response (fire fighting and ambulance) from different neighbourhoods of the city. Weighted overlay approach is utilized to aggregate above the criteria and find the most inhabitable neighbourhoods in the city. The study indicates the best area as "neighbourhoods with least crime and easiest accessibility to all mentioned fundamental services". Accessibility to each civic service is calculated by the service area and converted to a raster data which further aggregates them into a single raster using the above mentioned weighted overlay approach. After exporting the graphical model as a python script, the system is further developed to handle and return the dynamic influence rate based on the user inputs and ultimately the user obtains results for the best area. Then, the generated map automatically gets uploaded into the geo-server and the users can view the final liveability map on a dedicated web platform. Based on the approaches such as network analysis, multi criteria evaluation and decision support system, this study assists in selecting a neighbourhood on the basis of selected criteria by a particular user and also helps urban planners to identify design gaps in urban areas related to each criteria.
\end{abstract}

Key words: Decision Support System, Living conditions, Network Analysis, Web GIS, Urban planning, Accessibility analysis

\section{Introduction}

Developing countries in the world are undergoing a rapid urbanization process. According to the report presented by United Nations Department of Economic and Social Affairs (2014), 54\% of the world population lives in urban areas and that percentage is expected to be increased upto $66 \%$ by 2050 . Majority of the expected urban growth will be found from the developing countries of Asia and Africa. In the context of Sri Lanka, Colombo city is the most populated city in the country. Figure 1 demonstrates the growth of population over the previous census years which illustrates a steady increase in the population within the Colombo Municipality area. However, since the 2012 census enumeration was done based on normal residency, the population in 2012 appears to have decreased by 85,786 persons between 2001 census and 2012 census.

As a result of the population growth, populated areas are expected to face numerous challenges in meeting the fundamental needs of urban population such as housing, infrastructure, transportation, energy and employment as well as education and health care. Due to the huge competition for limited resources, the urbanization process causes adverse effects towards society. Rapid migration and housing construction result in overcrowding and spreading of slums, which cause serious issues like poor sanitation, poverty, increasing of crime rates and unemployment rate. On the other hand, the demand for vital natural resources is increasing and cause environmental sustainability problems due to population growth.

Accessibility to the civic services and clean environment is a factor that inhabitants usually consider when selecting a place to live. According to Raghavendran (2001), selection of living areas becomes a vital factor as it affects a person physically as well as emotionally. Penchansky \& Thomas (1981) defined the accessibility as "a concept representing the degree of fit between the client and the system". According to the work of Aday \& Anderson (1974) travel distance is a physical barrier for healthcare accessibility. Zhu et al. (2005) mentioned that accessibility represents the ease with which activities may reach from a given location by means of a particular transportation system. Inouye \& Berry (2008) analysed the elements related to bikeway infrastructure close to schools for a case study of three middle schools in Washoe country Nevada by using the GIS system. To evaluate the geographic accessibility using GIS several models are used including Euclidian distance, Thiessen polygons and cost path Analyses [Brabyn \& Skelly, 2002]. Kalogirou \& Foley (2006), 


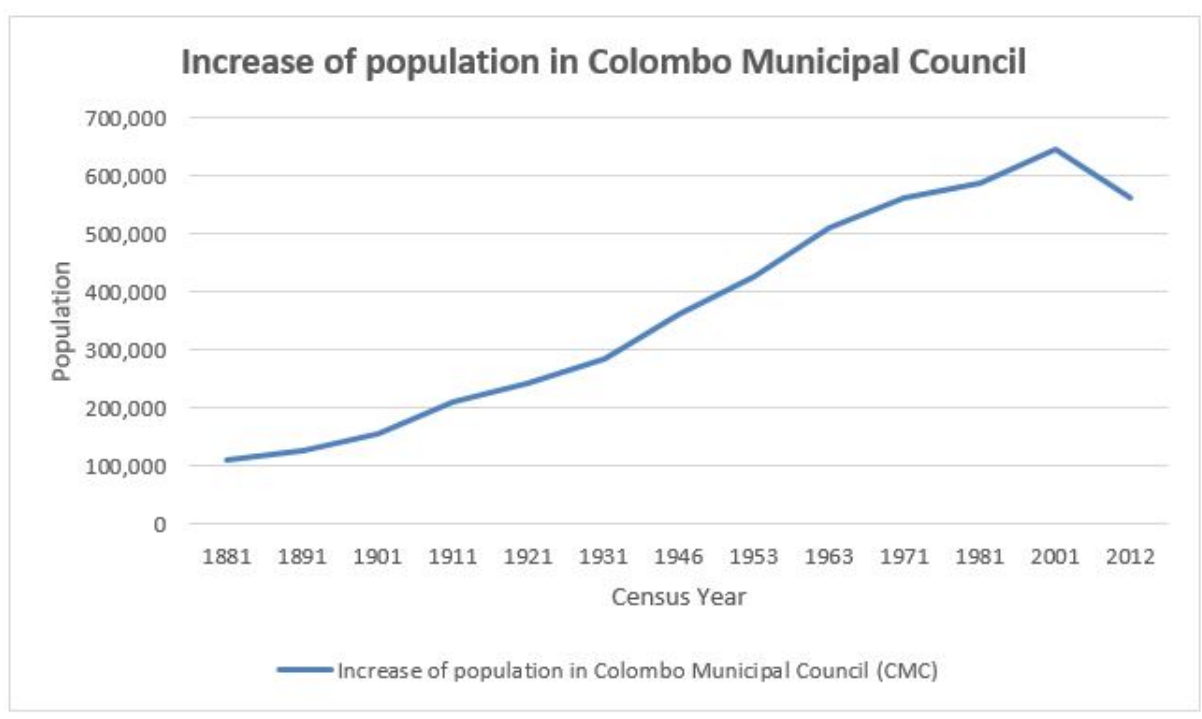

Figure 1: Colombo Municipal Council population growth (Source: Department of Census and Statistics, 2012)

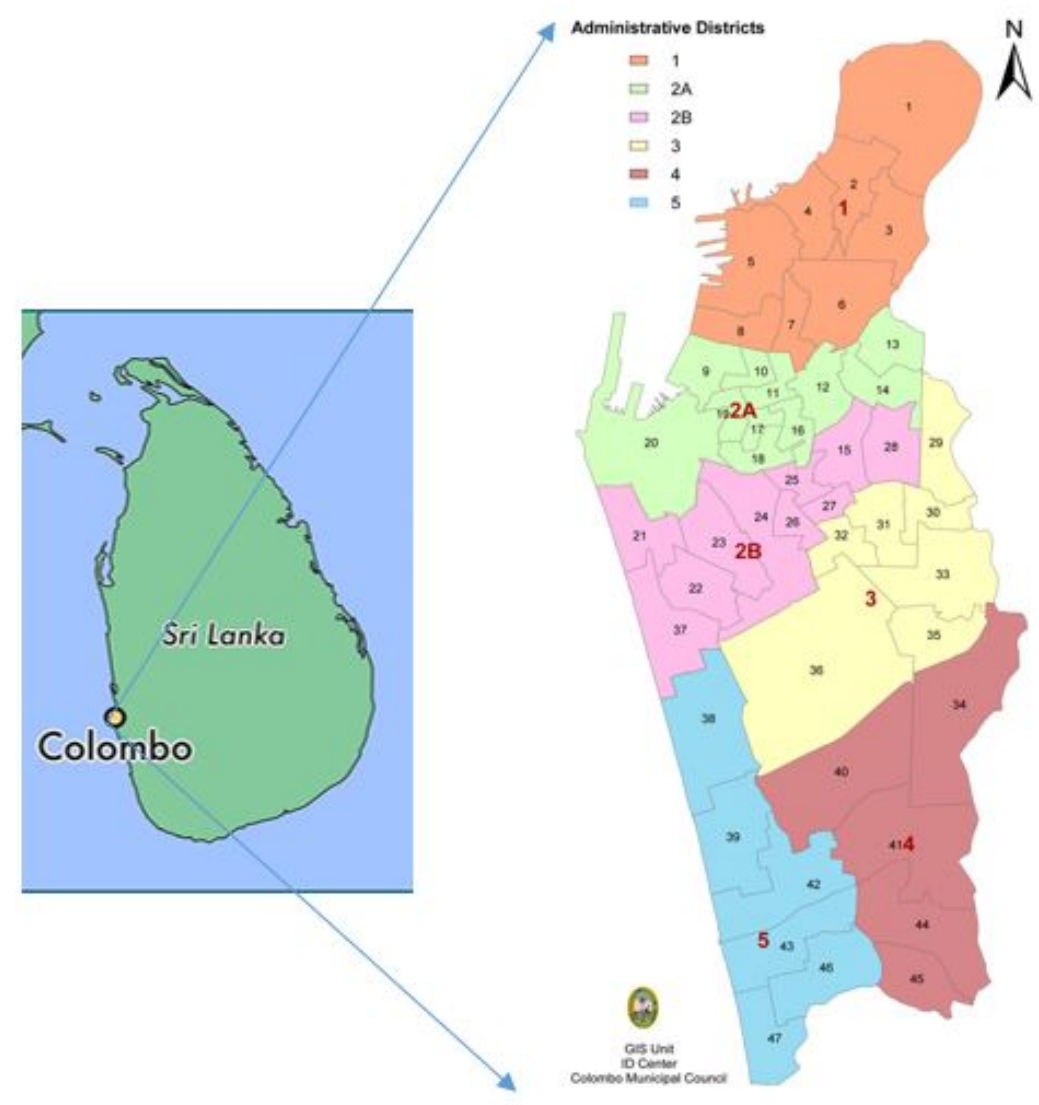

Figure 2: Research study area (Source: GIS unit of Colombo Municipal Council, 2017)

formed the approachability to the Irish acute hospitals along with the support of a GIS framework. They conducted this research corresponding to the Hanly report, which was modelled by the Irish government to regroup the major, general and local hospitals. Ohta et. al, (2007) have followed the Analytical Hierarchy Process (AHP) and GIS to upgrade the geographical approachability to the neurosurgical hospitals in Japan for the aged people.

In the method followed by Zhu et al. (2005), they made use of the multi criteria analysis (MCA) approach in order to evaluate the approachability to various factors for housing development. They interviewed 500 residents and briefed their responses to measure the average score of every factor and its ranking. According to the results of housing approachability criteria, a particular 


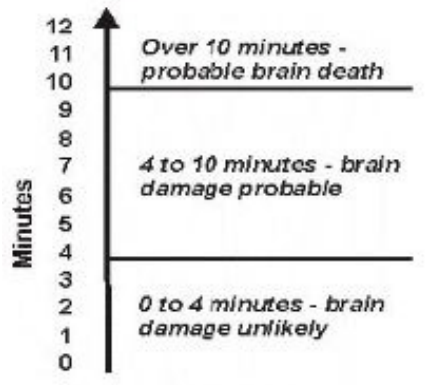

CPR Time Line

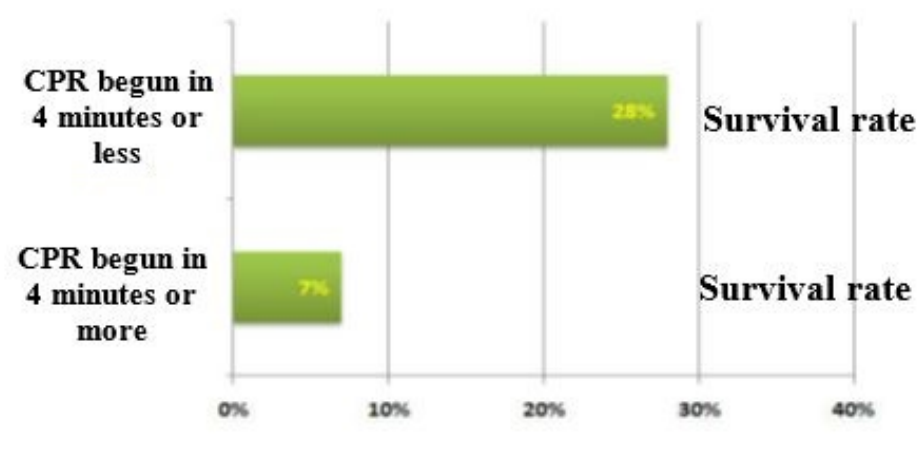

Figure 3: Survival rate and probable damage based on Cardiopulmonary resuscitation (CPR) timeline (Source: [ESRI, 2007])

conclusion formula was developed with the support of a multi-criteria analysis tool developed by JavaAHP.

Even though many people have conducted research on assessing living conditions and introduced many methodologies to evaluate living conditions, one of the common drawbacks is that the weight for each criterion is based upon analysing a particular questionnaire. On the other hand, using a questionnaire to collect data may have several disadvantages. Respondents may not be 100 percent truthful with their responses as they attempt to protect privacy and protect personal identity. Since living conditions are specifically based on personal requirements, individual decision making based on a sample dataset is neither acceptable nor reasonable. Therefore, in order to get an unbiased result for the living conditions, influence rate of each criterion should be dynamic according to the individual user requirement. According to Jankowski (1995), the role of GIS in spatial decision-making should aid the decision-maker in designating priority weights to the criteria, to evaluate the feasible alternatives and to visualize the results of his/her choice.

Web-based GIS systems is a type of distributed information system, having at least a server and a client, where the server is a GIS server and the client is a web browser, desktop application, or mobile application. Web GIS trend has been emerged for years and significantly reached to a whole new level. According to Szukalski, (2015) It's no longer is the question "if" or "when" to embrace Web GIS, the question now is "how" to leverage the new opportunities and workflows it enables. Zhang et al. (2015) developed a prototype Webbased Decision Support System for watershed management. They have used distributed hydrological models to evaluate the effectiveness of reducing non-point source pollution. Higher Secondary Education Board of Nepal use GIS as a tool for Educational DSS to manage information of half a million students [Banskota, 2009].

King Abdul Aziz university hospital and King Faisal Specialist hospital has established Saudi national diabetes registry. Subhani \& Al-Rubeaan, (2010) designed

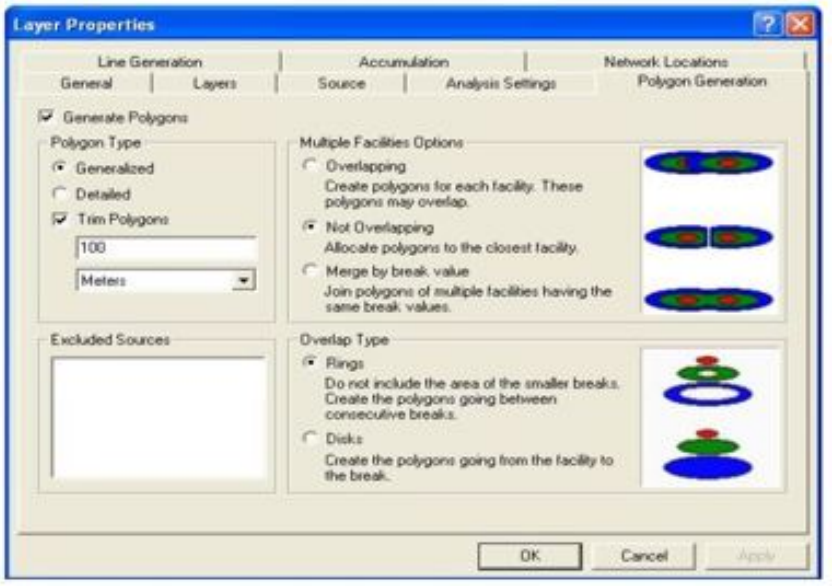

Figure 4: Polygon generation options

the registry with the goal to provide information of the extent and diabetes types, complication and treatment in the Kingdom. The registry is a web-based GIS system which offers data about the patients and their geographical location.

The concept, which lies behind this study, was borrowed from the study of Raghavendran (2001) which is extended here. He utilized a MCA to develop a Decision Support System (DSS) to upgrade the residential apartments located in the city of Chennai in India. He took the use of ten points and ranked them on a scale of ten variations. These factors consist of the approachability to city centre, education, railway stations, bus stations and health care services. The research also considered the convenience of some services such as groundwater, metro and sewerage system. The result of Raghavendran's study is a DSS, which opens the horizons to buyers and sellers in making immediate and appropriate decision in choosing a site for a home. As explained above one of the drawbacks in this methodology is that the weights are specifically based on a sample of users. Therefore we have implemented the decision support system in such a way that users can change the influence of each criteria based on his/her 
Table 1: Important fields in network dataset

\begin{tabular}{|c|c|}
\hline Field name & Usage \\
\hline & $\begin{array}{l}\text { Represent traffic flow direction. Values in this field are FT, TF, and } \\
\text { NULL. }\end{array}$ \\
\hline One-way & $\begin{array}{l}\text { - FT : Vehicles flow toward digitized direction } \\
\text { - TF : Vehicles flow opposite to digitized direction } \\
\text { - NULL : Vehicles flow both directions }\end{array}$ \\
\hline & Represent class of the road. In here 3 main types. \\
\hline Class & - Primary, Secondary and Local \\
\hline SHAPE_length & $\begin{array}{l}\text { Represents road segment length in meters. This field used to evaluate } \\
\text { length based analysis (Shortest path between two points) }\end{array}$ \\
\hline Time & Represents number of seconds require to travel certain road segment \\
\hline Address & Represents name of the roads. \\
\hline
\end{tabular}

requirements. Finally, the user can visualize the results based on his/her unique requirements. According to research done by Zamorano et al. (2009) ArcGIS network analyst extension effectively model transport base spatial analysis. Therefore, DSS was implemented by using ArcGIS network analyst extension as the core ArcGIS library to assess the accessibility to the educational facilities, health care facilities, markets, shopping malls and emergency services like fire and rescue services, ambulance services whilst multi criteria evaluation use to aggregate service area maps to find the best areas in the city. In this study, the term "Best" refers to the area which is accessible from the particular services defined by the user on the web environment. There could be number of services that cause liveability of inhabitants and these services differ from person to person. Based on different researches carried out in this field, certain services have been more prominently highlighted than the other services. Hence, these highlighted services have been used as parameters for the study.

\section{Methods}

This study is based on the methodology of accessibility analysis to different civic services and then aggregation of the results from accessibility analysis to interpret the "best" areas in the city. Nevertheless, the term "Best" does not explain being a qualitative term yet it varies from person to person. Albeit, this study prefers to use the term "Best" that indicates the area with the most accessibility to all the civic services.

\section{Study area}

Colombo is the largest and the fastest growing city in Sri Lanka and is also known as the financial and the commercial capital of the country. Colombo's geography is a combination of water and land. According to CIA's
(Central Intelligence Agency) world fact book (2018), the city has many canals and in the heart of the city there is a 65-hectare (160 acre) distinctive Beira Lake, which was used for centuries by colonists to defend the city. Besides, it has many environmental issues including coastal degradation from increased pollution; freshwater resources being polluted by industrial wastes and sewage runoff, inadequate waste disposal and air pollution. According to 2012 census enumeration report, Colombo municipal council area is about $37.29 \mathrm{~km}^{2}$, with a population of 561314 and a population density of 13364 people per $\mathrm{km}^{2}$. As illustrated in Figure 2, Colombo Municipal Council (CMC) is divided into 5 major administrative districts which are further divided into 47 wards for administrative purposes.

\section{Criterion Identification}

When considering the living conditions every person has his/her own requirements and priorities for choosing a neighbourhood for living. Also, it is essential to get information about peoples' necessities for defining a suitable neighbourhood for living. Therefore, a public survey was conducted to get the first-hand information on peoples choices. Current study mainly takes reference from the studies done by previous researchers to identify criterions for the analysis.

According to the public survey results, most people are interested to live in a low crime neighbourhood. By researching the crime rates and statistics for various areas, people can learn more about the safety of a town or neighbourhood. Therefore, crime statistics were taken as a criterion in this research.

Raghavendran (2001) conducted a survey in India to get the choices of people to locate a place for a housing project. The field survey results demonstrated that peo- 


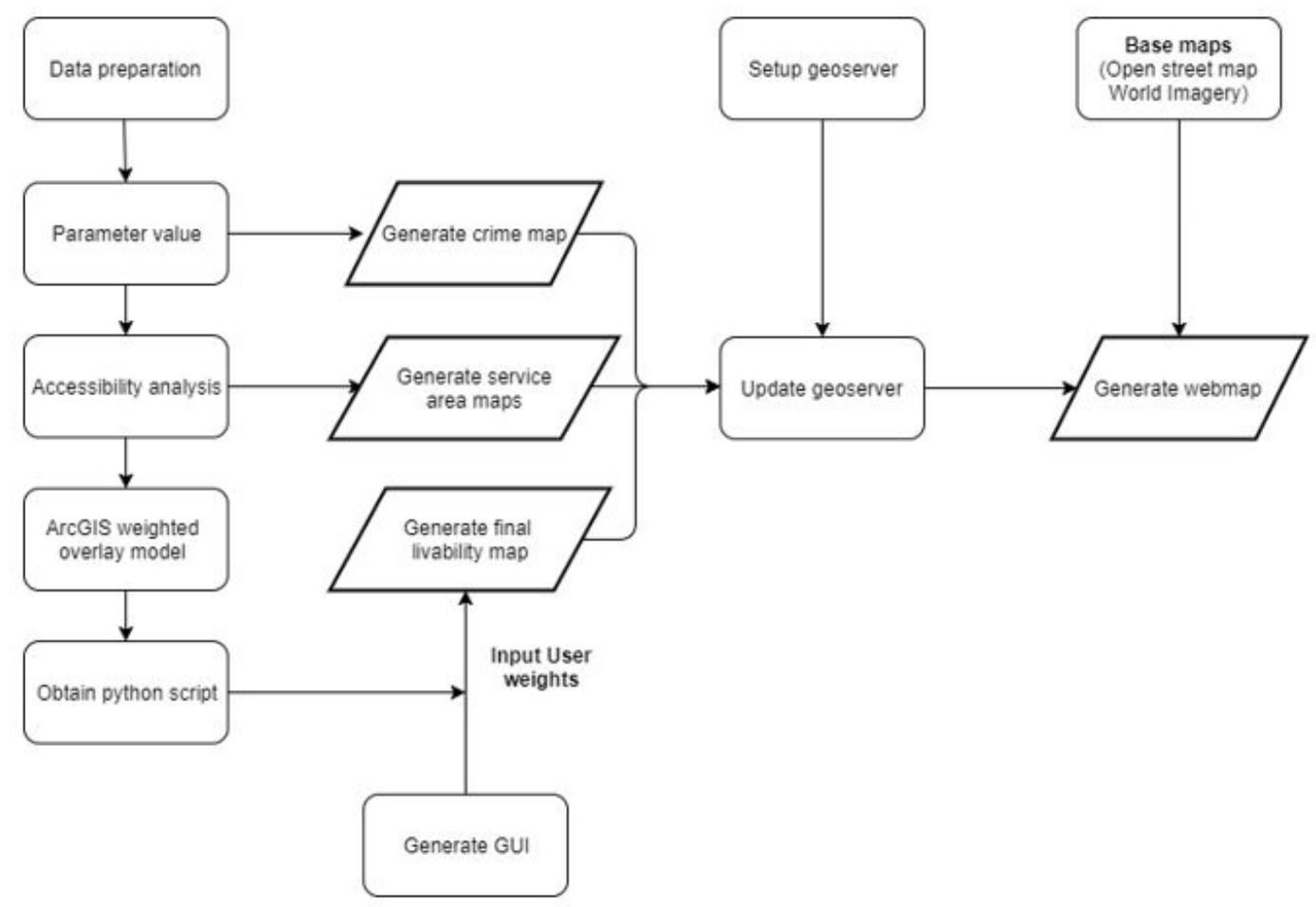

Figure 5: Overview methodology of the study

ple are more concerned on proximity to educational services and hospital services. Zhu et al. (2005) conducted a similar questionnaire in Singapore and got priorities for selecting a housing location. Results of the questionnaire demonstrated, 8 different criteria far more important than other. These services included shopping centres, health care public transport, banks, schools, community centres, post offices and parks. ESRI, et al. (2008) used GIS to analyse the approachability to green areas in Leicester city to various ethnic and religious communities. They made use of the network analysis to contrast between the green spaces accesses by different religious groups with benchmark standards for the delivery of green spaces in United Kingdom.

However, according to the human geography experts, certain services like emergency services, health care and educational services are more important and common for everyone. Therefore, the most common services that are important to everyone on daily basis (Schools, Green spaces, Hospitals, Emergency services) were considered in this research work. On the other hand, a number of services were kept limited due to unavailability of primary data (Noise, Traffic density, public transport, air quality). Most importantly, the current study provides a Decision Support System for the users to evaluate living conditions. In addition to existing criterion, users can make the analysis more sophisticated by adding additional criterions.

\section{Data preparation}

Source datasets used in this research are courtesy of various government organizations, such as Survey Department of Sri Lanka, Colombo municipal council, Ministry of Health etc. Before extracting information from source maps, all hardcopy maps were scanned and georeferenced to remove geometric errors.

\section{Road network}

Linear features like transport networks were represented as line features in GIS environment. In nodearc topological data models, a node established at every point where two line features of same feature class or different feature classes intersect. ESRI (Environmental Systems Research Institute) has introduced another data model known as Network data model. In this data model transport networks are represented as separate network data sets. Mainly three data sources were associated for creating a network data model with ArcGIS. They are junction, turn features and edges. Edge feature source is represented by line feature class, junction feature sources by point feature class and a turn feature source explicitly models a subset of possible transitions between edge elements during navigation [ESRI, 2009]. The network data model of ArcGIS incorporates advanced connectivity model that can represent complex scenarios, such as multimodal transportation networks. Table 1 demonstrates most important fields that is required to develop a network data model. Even though it is possible to build a network data model without these fields, the final results obtain from such network data 
Table 2: Characteristics of layers used in the study

\begin{tabular}{llll}
\hline Dataset name & Description & Type & Feature \\
\hline Road network & Feature class & Vector & Polyline, Represent streets \\
Hospitals & Feature class & Vector & Point, Represent hospitals locations \\
Schools & Feature class & Vector & Point, Represent schools locations \\
Fire and rescue station & Feature class & Vector & Point, Represent fire stations \\
Ambulance stations & Feature class & Vector & Point, Represent ambulance locations \\
Shopping malls & Feature class & Vector & Point, Represent major shopping malls \\
Green spaces & Feature class & Vector & $\begin{array}{l}\text { Point, Represent location of public } \\
\text { parks (centroid) and other green spaces }\end{array}$ \\
& & & $\begin{array}{l}\text { Area, Represent reported crime in each } \\
\text { Crime }\end{array}$ \\
& Feature class & Vector & \\
\hline
\end{tabular}

model will not be accurate. As an example, if there is no information about "one-way" restrictions then network analyst extension will consider all roads are traversable both directions.

\section{Crime data}

CMC is under 3 police zones (Colombo North, Colombo Central and Colombo South) which monitored by 22 police domains. Due to the higher level of security, actual positions of the crime incidents were not provided by police domains. Due to large number of police stations, accurate area controlled by each police station could not be obtained. Therefore thiessen polygons were generated to indicated areas that is controlled by each police station. Then these thiessen polygons were categorized to 4 equal intervals based on the total crime reported in 2016 .

\section{Civic services}

Colombo being one of the major cities in Sri Lanka has a well distributed network of health care services. Hospitals are categorized as government, private, armed forces and prison. Hospitals that relate to prison and armed forces only allow patients from their own agencies. Hence these hospitals were not considered and a total of 24 hospitals were taken into consideration in this research. Out of the 24 hospitals, 13 hospitals belong to the government sector and 11 to the private sector. In Sri Lanka, the types of educational institutions available are schools, universities and private tuitions. The above mentioned educational services belong to the government, semi-government and private sector. In this study only national schools which offer education from grade I to grade XIII were considered because they are the institutions funded by the government. Primary, junior secondary and collegiate schools are not considered due to incomplete grade levels.

There are certain emergency response services that a person may require at any time of the day. Out of them, the most important services are the ambulance services and the fire-fighting services. Therefore, these services are very time critical [ESRI, 2007]. The minimum response time of these services may save a lot of financial loss and human lives. These two services are functioning under various private and public authorities. The fire and rescue services are carried out solely by Colombo Municipal Council fire and rescue division. They are covering the whole CMC area with only six sub stations. All the major private and government hospitals in CMC area provide ambulance services to the public. In addition to that, government launched a new ambulance service free of charge in collaboration with the government of India. Table 2 demonstrate characteristics of every dataset used in the network dataset model.

\section{Parameter values}

The fundamental factor for the study is the "Travel time". Varying time intervals have been used to analyse which areas of the city are closer to the world standards approachability to a particular service. Travel time was considered as the impedance factor in this research since CMC area is densely populated and also one of the highest traffic density cities in the country. In the case of a medical emergency, time is a critical factor. Survival rates for certain varieties of medical emergencies are based upon brisk response of well-trained medical personals. According to Figure 3 the time between the beginning of the heart attacks and administration of the definitive care proved to have a pronounced effect on survival.

According to the study of Mayer (1979), if the travel time exceeds 12 minutes, $17 \%$ of the victims lived long enough to be admitted in the hospital and $6 \%$ survived to be discharged. With a travel time of 6 minutes or less to the definitive care, $52 \%$ survival rate has been observed. 

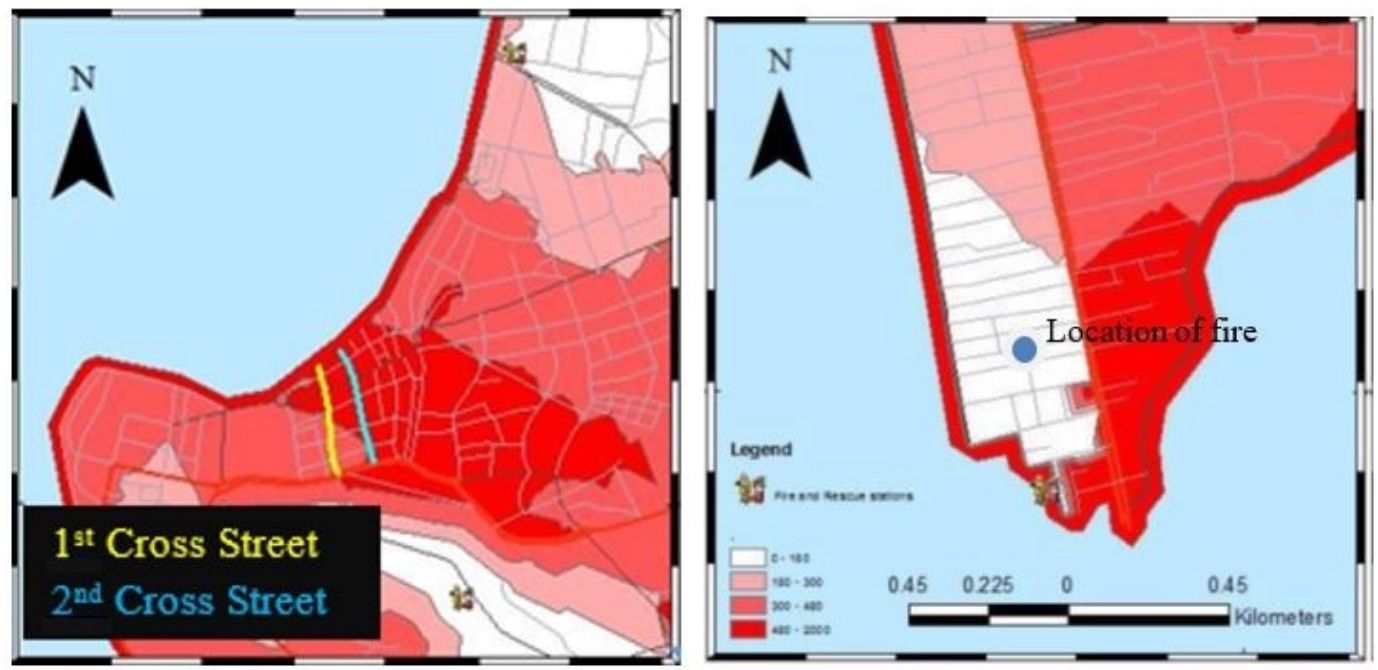

Figure 6: Previous fire eruptions

Based on the CPR timeline on Figure 3 it is more logical to assign initial time interval within 3 minutes to reach a definitive medical care, since brain damage is unlikely within that time period. Therefore this research considers time intervals of 180 seconds ( 3 minutes), 300 seconds ( 5 minutes), 480 seconds ( 8 minutes) and greater than 480 seconds to reach a definitive medical care.

There is a stage of every fire where the speed of the fire increases drastically, which is known as "flash over". The Flash over occur when the room temperature reaches $600^{\circ} \mathrm{F}$ to $700^{\circ} \mathrm{F}$ [Kennedy \& Kennedy, 2004]. According to Mansfield fire fighters, flashover may typically appear less than 4 minutes. Hence, a location of a neighbourhood can be considered as a safe zone if Fire trucks can arrive before the flashover (4 minutes). Therefore, this research considers time intervals of 3 minutes, 5 minutes and 8 minutes.

\section{Accessibility Analysis}

Service area calculation has been used to evaluate accessibility for each criterion in this research. With the ArcGIS Network Analyst extension, you can find service areas around any location on a network. ESRI (2009) defined, a network service area is a region that encompasses all accessible streets (i.e. streets that are within specified impedance). In this study, service area was calculated according to the parameters described in Table 3.

Output of the network service area is a polygon layer, usually polygons around each facility overlap with other polygons, properties of service area layer allows to define instructions for these overlapping polygons. As illustrated in Figure 4, there are three ways for polygon generation, they are non-overlapping, overlapping and merge by breaks.

The first minor objective of current study is to recognize only the locations accessible within a certain time frame and it is not essential to check each facility and its corresponding service area. Therefore, the third option (Merge by break value) was used in this research.

\section{ArcGIS weighted overlay model}

In order to aggregate criteria most researches have used Weighted Sum analysis or Weighted overlay analysis and weights which obtained from a questionnaire. In this research weighted overlay analysis was selected rather than using weighted sum analysis, because weighted sum analysis does not allow rescale values. Then generated weighted overlay model was exported into a python script to integrate with web-based Decision Support System.

\section{Web-based Decision Support System}

Most of the researchers who carried out studies on finding "best area" for living are based on the results obtained from the public. Therefore, implementing a user-friendly decision support system is the only solution to the problem. By a decision support system user can change the importance of each criteria according to their preference and generate an independent result rather than a bias result based upon the questionnaires.

Graphical User Interface (GUI) was generated using "Page" application. PAGE is a drag-and-drop python GUI generator which resembles Visual Basic. It allows to easily create GUI windows containing a selection of Tkinter (Tkinter is the standard Graphical User Interface library for python) widgets. All client-side processing activities are performed using exported ArcPy modules. ArcPy is a site package that builds on (and is a successor to) the successful ArcGIS scripting module. According to ESRI (2009), ArcPy goal is to create the cornerstone for a useful and productive way to perform geographic data analysis, data conversion, data management, and map automation with Python. GeoServer is a software server based upon Java, providing facilities to users to 
Table 3: List of parameters and evaluations criteria

\begin{tabular}{lccccc}
\hline No & Parameter Name & Evaluation criteria & \multicolumn{3}{c}{ Intervals } \\
\hline 1 & & $\mathbf{1}^{\text {st }}$ & $\mathbf{2}^{\text {nd }}$ & $\mathbf{3}^{\text {rd }}$ \\
\hline 2 & Hospitals & Time (Seconds) & 180 & 360 & 600 \\
3 & Ambulance & Time (Seconds) & 180 & 300 & 480 \\
4 & Fire fighting & Time (Seconds) & 180 & 300 & 480 \\
5 & Shopping malls & Time (Seconds) & 300 & 600 & 900 \\
6 & Green spaces & Distance (meter) & 400 & 1000 & 1500 \\
\hline
\end{tabular}
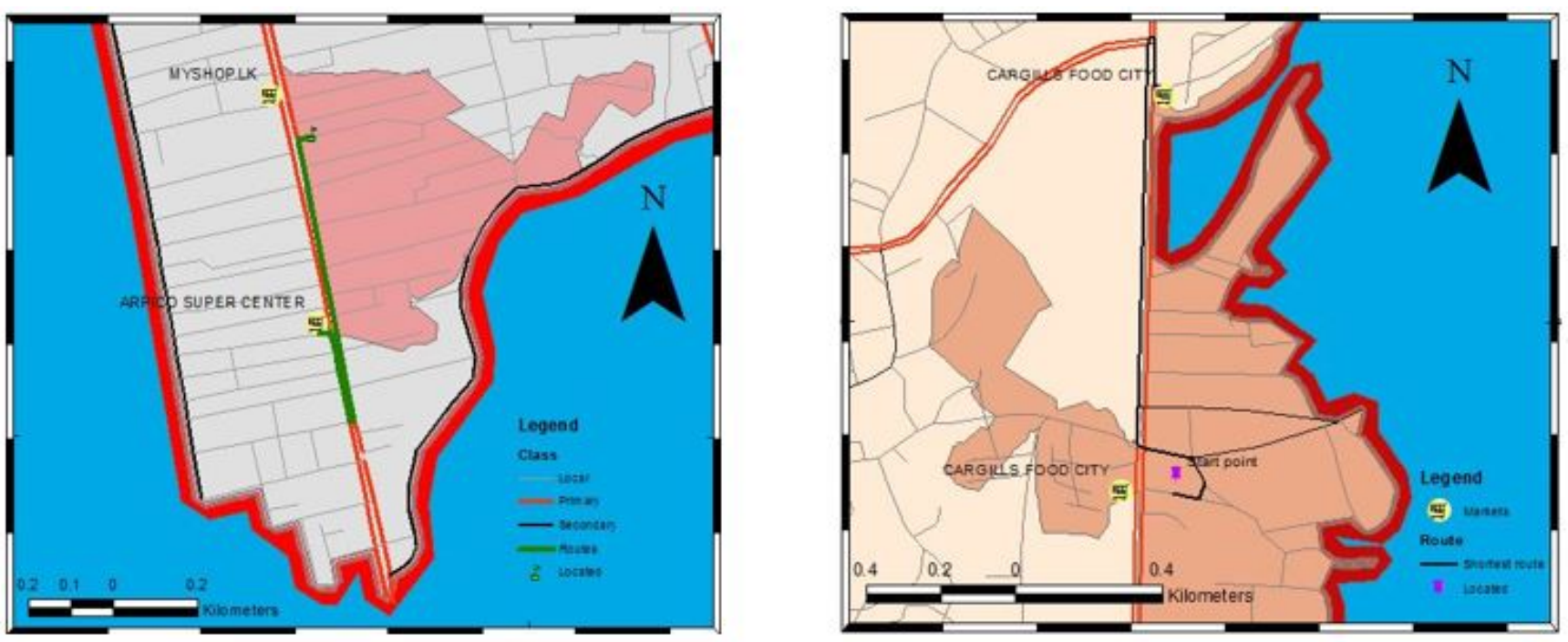

Figure 7: Results of the closest facility analysis

visualize and manage geospatial data. After preparing a workspace to store all the maps related to the research, shapefiles were uploaded into the workspace by giving all the resource information (Layer name, Coordinate Reference Systems and Bounding Boxes).

In this research, a separate web platform was also prepared to visualize the data in an interactive way. Most of the interactive capabilities in this web platform were programmed with leaflet JavaScript library. Leaflet is an open-source JavaScript library specially used for mobile-friendly interactive maps and designed with performance, simplicity and usability in mind. Figure 5 outlines the approach which used to develop the Decision Support System by integrating multi-criteria analysis and Web-GIS.

\section{Results and Discussion}

\section{Accessibility analysis}

The first objective of this research is to determine the service gaps of the neighbourhoods based on the unavailability of civic services. In order to archive the first objective, service areas have been calculated using
ArcGIS network analyst extension. The accuracy and the reliability of accessibility analysis were based on the data layers used in the research.

\section{Road network}

CMC is an urban area which has a complex road structure with twin roundabouts, one way roads, and two-way dual carriageways. In order to model road network accurately roundabouts have been digitized as it is connecting all roads into a single node.

CMC is a very populated area with high traffic density. Therefore travel time was used as impedance when performing the accessibility analysis. Thus, interpreting travel duration to each road segment is a critical factor in the accessibility analysis. Travel speed of connecting roads in between twin roundabouts was assumed same as the speed of the roundabout.

\section{Green spaces}

A total of forty seven green space locations have been included in this research that are accessible by people. One of the major issues that have been faced during digitizing the green spaces is that these features are 

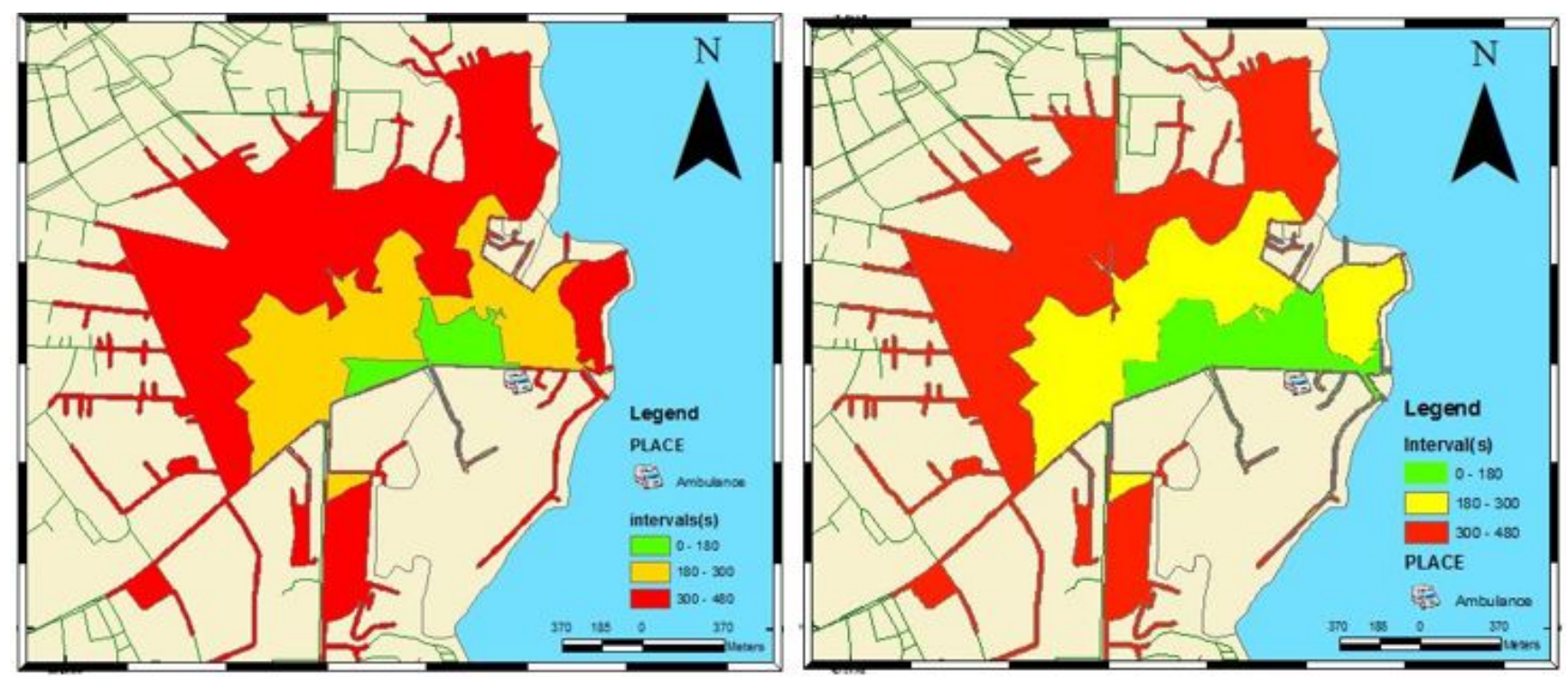

Figure 8: Comparison of service area before and after road improvement

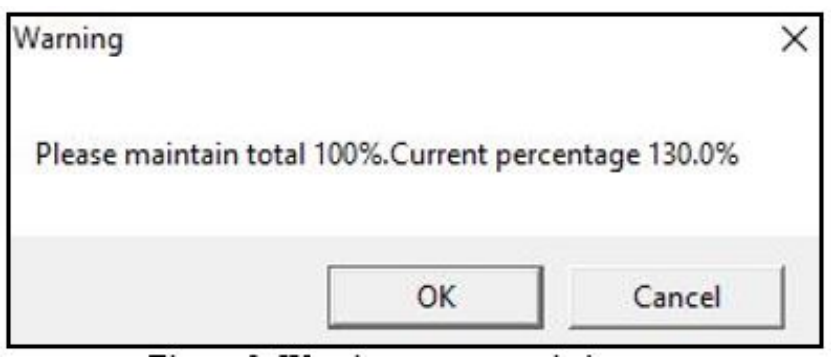

Figure 9: Warning message window

normally area features but when performing network analysis, extension only accepts facilities as a point feature. Therefore centroid of each green space have been implemented and used as facilities for the network accessibility analysis. In this research, accessibility is calculated considering U turns and One-way restrictions. When considering the accessibility for green spaces people often travel on foot rather than by vehicles. Also a standard of half-mile has been identified as a reasonable distance to walk to a park [Sherret, 1979].

In order to model the accessibility to green spaces more accurately, entrances to the green spaces can be used. Also there are certain instances where the green space has multiple entry points. In such cases by including all those entries as point features the accuracy of the analysis can be improved. Due to the limited time frame it was unable to collect entry points to all green spaces by visiting these places.

\section{Fire and Rescue services}

A total of six fire and rescue stations are there all over the CMC jurisdiction. It has been observed that majority of the CMC area is not accessible within three minutes. Also there are certain neighbourhoods which are not accessible even within eight minutes from sta- tions. According to the statistics, only $11 \%$ of total land cover is accessible within 3 minutes and $40 \%$ of total land cover is over 8 minutes of accessibility from nearest service station which is way over the flashover. Overall around $70 \%$ of the total land cover is in potential to get affected from a fire critically.

According to the distribution of fire and rescue services, eastern part of $\mathrm{CMC}$ jurisdiction has much more potential to be affected from a fire. There are certain locations which are highly potential to catch a fire but are also spatially situated near to a fire or a rescue station. Studying the past fire eruption which marked in Figure 6 , it has been validated that this area has been highly affected by fires. Based on the analysis Borella North, BorellaSouth, Dematagoda, Gothamipura, Grandpass South, Khettarama, Kirula, Kirulapone,Maligawatta East,Narahenpita,Nawagampura,Pamankada

East,Pettah,Sammanthranapura and Wanathamulla GN divisions have high potential to be critically affected in case of a fire eruption.

Based on the accessibility of markets and shopping malls more than $80 \%$ of total land cover is accessible within $300 \mathrm{~m}$ from a shopping centre. These major shopping centres are well distributed. As Illustrated in Figure 7 , the service areas of some shopping centres are reduced due to road restrictions, even though they are spatially situated in close proximity.

par Analysis result of ambulance services demonstrates an interesting pattern which indicates that most of the ambulance services are clustered around Central Colombo. Due to the traffic restrictions and being a dual carriageway, the service areas of certain ambulance stations decreased even though they are spatially located in close proximity. As an example, ambulance from Castle Street hospital can only cover a very small part within 3 minutes of standard time frame (left image of Figure 


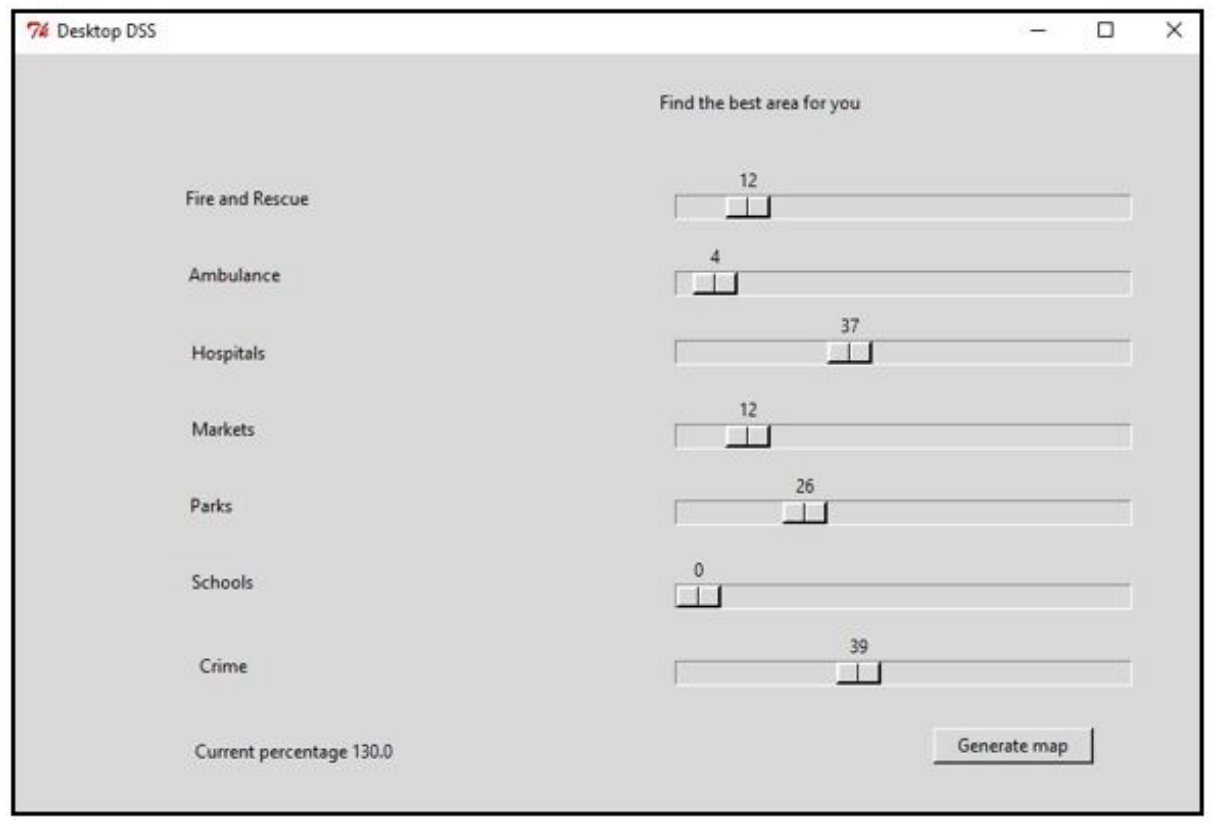

Figure 10: Graphical user interface for the desktop DSS

8). However, by adding connections between dual carriage way, the service area of ambulance can be increased (right image of Figure 8).

The main reason to limit connections between dual carriage ways is to decrease the road traffic but in emergency situations this may cause life threat to patients. However, both above problems can be minimized by allowing the use of connecting roads only for emergency vehicles. Investigating crime in CMC jurisdiction has been an arduous task due to high security reasons. Also obtaining data related to crime needs high security clearance from Inspector General of Police. Detailed reports of crimes which include location, type, date and time of crime etc. are available in police stations of the relevant area. Police headquarters has data available only for the total reported crimes in each year based on the crime type. The control domain map of each police station is available in relevant police stations, which include 21 police stations. Due to limited time period it was difficult to obtain maps of each police domain. Therefore, as an alternative solution, thiessen polygons were generated in each police station and assumed as police domains.

\section{Web-based Decision Support System}

The most excellent feature of this decision support system is that it supports real-time decision making with intuitive interfaces. The results from questionnaire showed that DSS can meet demands of users to find out the best neighbourhoods in cities. In addition, the prototype DSS is scalable which developers can add more and more data sets for the analysis. But for this research only seven most important criteria have been used.

One of the setbacks in the system is that the system is implemented as a thick client solution where all the processing functions can be performed on the client side. Therefore, performance of DSS depends on the hardware of the client-side. Also one of the major reasons to implement the system as a thick client solution is that geo server does not support publishing of geo-processing services like Arc Server. In order to minimize the use of commercial software and the gap between commercial and open source software, the system was implemented as a thick client where all the processing activities were performed on the client side.

All data sets related to the DSS is stored in geo server which is useful for regular updating and therefore the users can always perform analysis with up to date datasets. Unlike in commercial software, open source softwares have certain disadvantages such as lack of technology support and rapid building up.

In addition to visualizing the generated map on web browser, a shape file of the final map was generated on the local storage where users can perform other analysis using software related to GIS. Implemented DSS does not depend on the study area and it can be applicable and implementable on any environment or a neighbourhood to evaluate the living conditions.

\section{User interface}

In order to improve the user friendliness of decision support system, a separate user interface in Figure 10 was implemented to change the influence percentage of each criterion for the final result based on the user requirement.

Current percentage in Figure 9 represents an addition of each criterion which is updated on the change of each scale. In order to generate the final map, current 


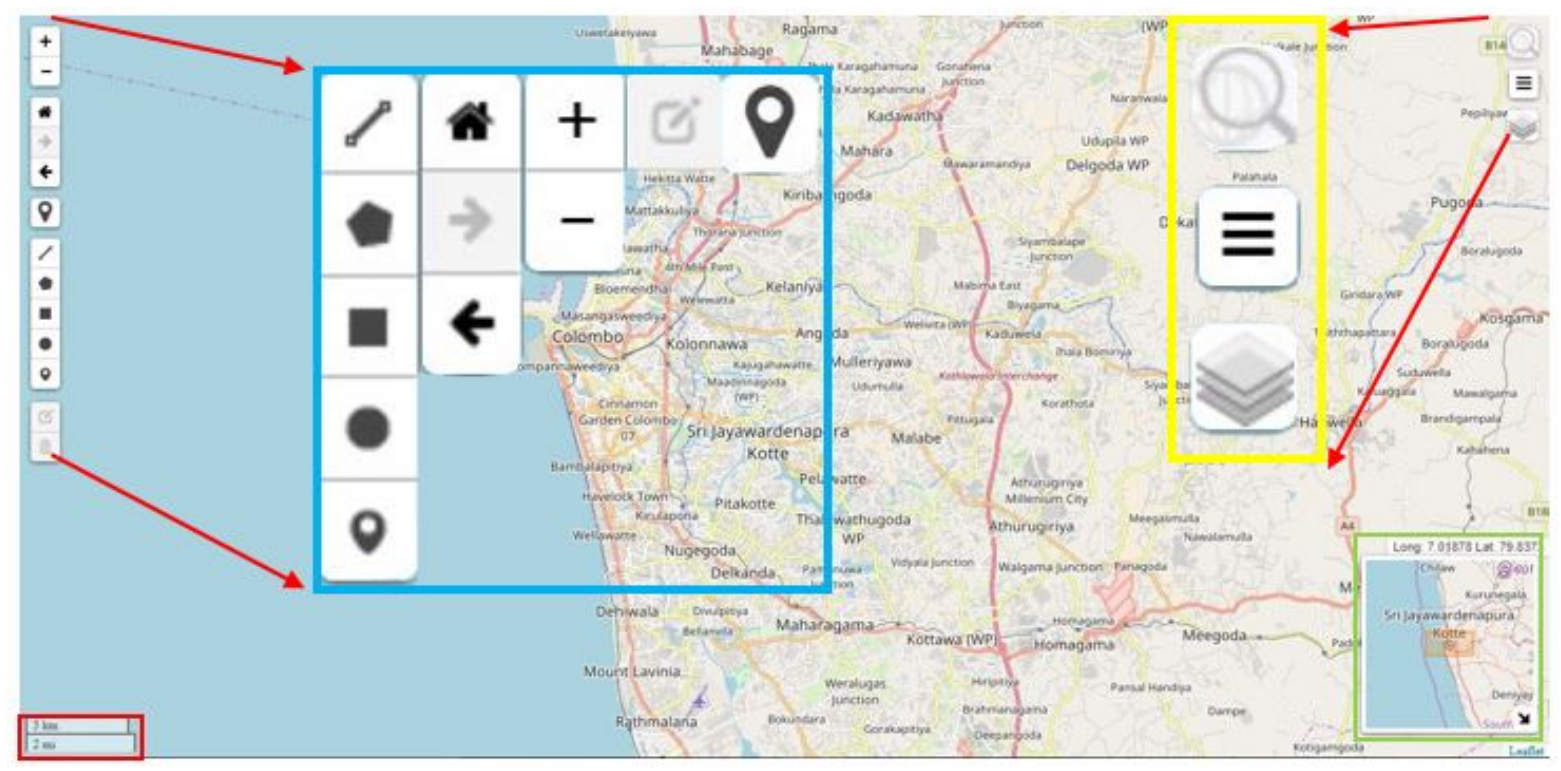

Figure 11: Web map and its components

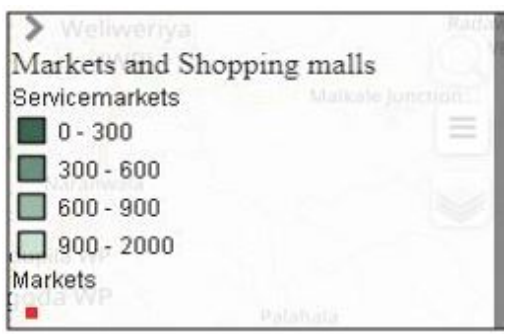

Figure 12: Sample legend

percentage should be maintained $100 \%$. If users try to generate a map without maintaining $100 \%$ a warning message will appear mentioning to maintain $100 \%$ total influence.

The main components of the web map are represented in four colour boxes in Figure 11.

\section{Red color box}

(a) Represents the Scale of the map window in $\mathrm{km}$ and miles.

2. Green color box

(a) Represents an overview of the suburban areas of the map window.

(b) Represents geographical coordinates of the position of cursor on map.

3. Yellow color box

(a) Searching capability based on open street map data

- When a user hovers on the magnifier icon on the map window a search box will be appeared and then the users can enter the location based data and search it on the map.

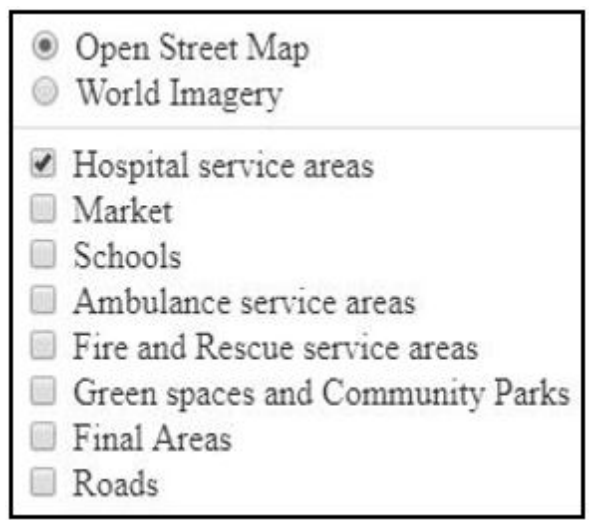

Figure 13: Layer switching

(b) Map legend for included layers

- When a user clicks over the legend icon, legend for each map layer appears and users can obtain legend information.

- Figure 12 illustrates the legend information for markets and shopping malls service areas.

- By sending the Get Legend Graphic request to geo server, legend for each graphic layer can be obtained.

(c) Map layers

- Figure 13 represents the base map layers and overlay map layers which are available for visualization (Accessibility maps for different civic services and crime maps).

- Also users have the ability to switch the base map layer into a satellite view and street view.

- By switching on-off every layer, users can compare locations on the base map. 

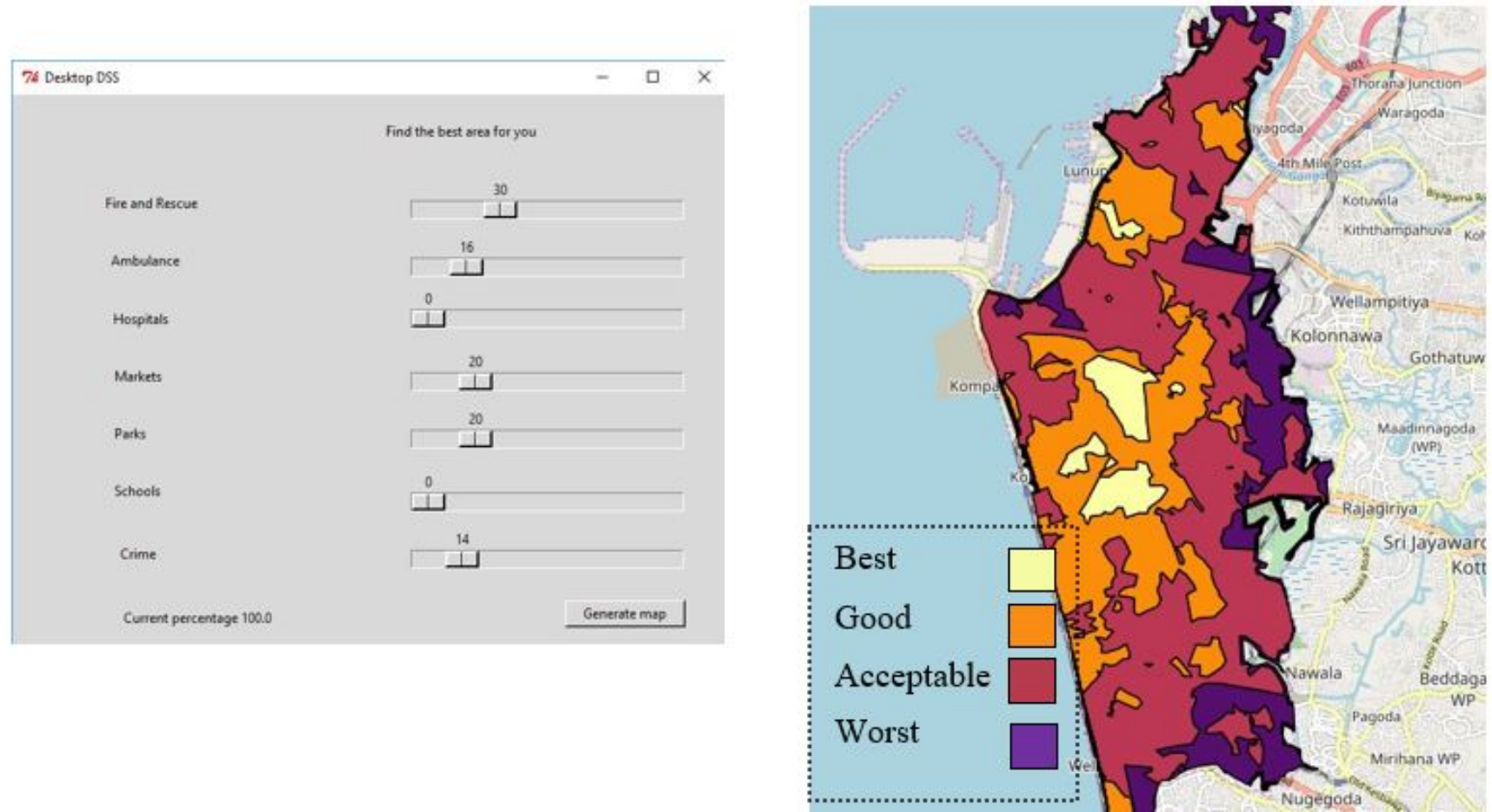

Figure 14: Sample output map based on selected criteria by a user

- Maps were retrieved into the browser by sending a GetMap request to the geoserver.

4. Blue color box

(a) $1^{\text {st }}$ column: Uses to digitize map objects on webmap as point line and polygon.

(b) $2^{\text {nd }}$ column: Uses to go to the previous zoom levels and home zoom level.

(c) $3^{\text {rd }}$ column: Uses to zoom in and zoom out.

(d) $4^{\text {th }}$ column: Uses to edit or delete the created map object.

(e) $5^{\text {th }}$ column: Show user's current location on map based on network data.

Figure 14 represents a sample output according to the user defined influence rates on Graphical User Interface of DSS.

As explained by most of the researches and studies, stakeholders have significant influence on the accomplishment of any project. This is extremely important in certain incidents such as when the stakeholders are various individuals and are not associated with same establishment. Due to different stakeholders having different requirements, it is necessary to recognize and engage these stakeholders as early as possible (during system designing). In this case, three major stakeholders have been identified: system developers, urban planners and public users, all relying on different parts of DSS. System developers are concerned on the efficiency and effectiveness of the DSS; urban planners are concerned on the effective land use planning based on the accessi- bility analysis results whilst general public is concerned about the information of the living conditions. To fulfil these requirements, technologies such as Web GIS, Desktop GIS have been utilized. This DSS is in the earliest stage of an implementation cycle. Prototype of DSS has been implemented mainly for the purpose of demonstrating living conditions based on user requirements. Hence, current system is not a fully equipped DSS.

The future versions of DSS will be enhanced to a fully functional decision support system for urban planners to simulate the change of service area when proposed civic service stations are added. As an example, how service areas can change if an emergency service station is added to the existing system. Currently, the DSS consists of two main parts as desktop and browser. By integrating desktop into the browser users will not have to use a desktop application. This can be accomplished by implementing the system as a thin client solution. Also, this will reduce the application processing time because all the processing activities are performed on the server side. Therefore processing speed does not depend on the client side and the hardware will receive the final output.

\section{Conclusion}

The main objective of this research is the implementation of a decision support system to evaluate the living conditions based on the user requirements. In order to achieve the main objective, 3 minor objectives were identified.

The first minor objective was to determine the ser- 
vice gaps in the cities based on the unavailability of services. According to the results of each criterion, it is found that only school services and markets service areas are well distributed within the CMC jurisdiction and all other civic services have a poor distribution in $\mathrm{CMC}$ jurisdiction. Therefore, in order to improve the living conditions of each part of the CMC, new service stations for hospitals, green spaces and emergency services should be established by conducting a proper research. It has been observed that, apart from establishing new stations, service areas can be improved by doing simple modifications for the existing road networks (For Ambulance and Fire and Rescue services) and relocating existing service stations to other places.

The second objective was to develop a DSS to evaluate the living conditions based on the user requirements. By integrating ArcPy, python and geo server as a geographical data server, desktop decision support system was implemented. There are certain advantages with the implemented DSS:

(1) DSS is implemented with cloud computing technology

(2) User friendly GUI largely enhance user experience

(3) Can be implemented to any area by expanding data sources

The final objective was to develop a dedicated web platform to link desktop decision support system to compare generated final liveability map and service area maps on a base map layer. The web platform is implemented by open source JavaScript libraries. With implemented DSS users can view generated liveability map on a web browser and compare with different base map layers including Satellite view maps and street view maps.

\section{References}

Aday, A. \& R. Anderson (1974) A Framework for the Study of Access to Medical Care. Health Service Research, v. 9(3),pp.208 -220.

Banskota, T.R. (2009) Application of GIS as Educational Decision Support System (EDSS), 'an experience of Higher Secondary Education Board'. Nepal Proceedings of ESRI Education User Conference 2009. Department of Census and Statistics (2012) Census of Population and Housing. Population and Demography Division: Colombo 07.

Brabyn, L. \& C. Skelly (2002) Modelling population access to New Zealand public hospitals. International Journal of Health Geographic, v. 1(3).

DOI:https://doi.org/10.1186/1476-072X-1-3

Central Intelligence Agency (2018) The world factbook. Central Intelligence Agency: Washington.
Comber, A., C. Brunsdon and E. Green (2008). Using a GIS based network analysis to determine urban green space accessibility for different ethnic and religious groups. Landscape and Urban Planning, v. 86(1),pp. 103-114.

DOI:http://dx.doi.org/10.1016/j.landurbplan.2008. 01.002

ESRI (2007) 'GIS for Fire Station Locations and Response Protocol an ESRI White paper.' ESRI: New York.

ESRI (2009) 'ArcGIS Network Analyst Software help manual version 9.3 .'

Inouye, D.K. \& K.A. Berry (2008) Assessing Bikeway Networks around Public Schools: A Tool for Transportation Planning in Washoe County. Nevada Planning Practice and Research, v. 23(2),pp. 229-247. DOI:https://doi.org/10.1080/02697450802327164

Kalogirou, S. \& R. Foley (2006) Health, Place and Hanly: Modeling accessibility to hospitals in Ireland. Irish Geography, v. 39(1),pp.52-58. DOI:https://doi.org/10.1080/00750770609555866

Kennedy, P.M \& K.C. Kennedy (2004) Flashover and fire analysis. A Discussion of the practical use of Flashover Analysis in fire investigations. Proceeding of INTERFLAM conference, 2004. Retrieved from: https://www.researchgate.net/publication/ 238068602_FLASHOVER_AND_FIRE_ANALYSIS_Discussion_of_The_Practical_Use_of_Flashover_ Analysis_In_Fire_Investigations

Ohta, K., G. Kobashi, S. Takano, S. Kagaya, H. Yamada, H. Minakami \& E. Yamamura (2007) 'Analysis of the geographical accessibility of neurosurgical emergency hospitals in Sapporo city using GIS and AHP' International Journal of Geographical Information Science, 21(6). pp. 687-698. DOI:https://doi.org/10.1080/13658810601135692

Jankowski, P (1995) 'Integrating geographical information systems and multiple criteria decision-making methods'. International Journal of Geographical Information Systems, v. 9(3),pp.251-273.

DOI:https://doi.org/10.1080/02693799508902036

Mayer, J.D. (1979) Emergency medical services: delays, response time and survival. US National Library of Medicine, v 17(8),pp.818-827. DOI:http://dx.doi.org/10.1097/00005650197908000-00004

Penchansky, R.\& J.W. Thomas (1981) The concept of Access. Medical Care, v. 19(3).pp.127-140 DOI:http://dx.doi.org/10.1097/00005650198102000-00001

Raghavendran, S. (2001) 'Decision support system for promotion of residential apartments in Chennai city 
using GIS'. Proceedings of "Map India" conference 2001.

Subhani, S.N. \& K. Al-Rubeaan (2010) Design and Development of a Web-Based Saudi National Diabetes Registry. Journal of Diabetes Science and Technology, v 4(6).pp.1574-1582.

DOI:https://doi.org/10.1177/193229681000400635

Szukalski, B (2015) Six Trending topics of WebGIS. URL:https://blogs.esri.com/esri/esri-insider/2015/ 08/05/six-trending-topics-web-gi

United Nations Department of Economic and Social Affairs (2014) 'World Urbanization prospects: the 2014 Revision'. United Nations: New York.

Zamorano, M., E. Molero \& A. Grindlay (2009) A planning scenario for the application of geographical information systems in municipal waste collection: A case of Churriana de la Vega (Granada, Spain) Resources. Conservation \& Recycling, v 54(2).pp.123-
133 .

DOI:http://dx.doi.org/10.1016/j.resconrec.2009.07. 001

Zhang, S., Y. Li, T. Zhang \& Y. Peng (2015) An integrated environmental decision support system for water pollution control based on TMDL- A case study in the Beiyun River Watershed. Journal of Environmental Management, v 156(1).pp.31-40.

DOI:https://doi.org/10.1016/j.jenvman.2015.03.021

Zhu, X., S. Liu \& M.C. Yeow (2005) A GIS-Based Multi-Criteria Analysis Approach to Accessibility Analysis for Housing Development in Singapore. Proceedings of SSC Spatial Intelligence, Innovation and Praxis: The national biennial Conference of the Spatial Sciences Institute, Melbourne.

Sherret, A. (1979) BART's First Five Years; Transportation and Travel Impacts. Peat, Marwick, Mitchell \& Co.: San Francisco 